\title{
Empirical analysis and modeling of Argos Doppler location errors in Romania
}

\author{
Laurentiu Rozylowicz $^{\text {Corresp., }}{ }^{1}$, Florian P Bodescu ${ }^{2}$, Cristiana M Ciocanea ${ }^{1}$, Athanasios A Gavrilidis ${ }^{2}$, Steluta \\ Manolache $^{1}$, Marius L Matache $^{1}$, Iulia V Miu ${ }^{1}$ ， Ionut C Moale ${ }^{2}$, Andreea Nita ${ }^{1}$, Viorel D Popescu ${ }^{1,3}$ \\ ${ }^{1}$ Center for Environmental Research and Impact Studies, University of Bucharest, Bucharest, Romania \\ 2 Multidimension R\&D, Bucharest, Romania \\ 3 Dept. of Biological Sciences, Ohio University, Athens, Ohio, United States of America \\ Corresponding Author: Laurentiu Rozylowicz \\ Email address: laurentiu.rozylowicz@g.unibuc.ro
}

Background. Advances in wildlife tracking technology have allowed researchers to understand the spatial ecology of many terrestrial and aquatic animal species. Argos Doppler is a technology that is widely used for wildlife tracking owing to the small size and low weight of the Argos transmitters. This allows them to be fitted to small-bodied species. The longer lifespan of the Argos units in comparison to units outfitted with miniaturized global positioning system (GPS) technology has also recommended their use. In practice, large Argos location errors often occur due to communication conditions such as transmitter settings, local environment, and the behavior of the tracked individual.

Methods. Considering the geographic specificity of errors and the lack of benchmark studies in Eastern Europe, the research objectives were: (1) to evaluate the accuracy of Argos Doppler technology under various environmental conditions in Romania, (2) to investigate the effectiveness of straightforward destructive filters for improving Argos Doppler data quality, and (3) to provide guidelines for processing Argos Doppler wildlife monitoring data. The errors associated with Argos locations in four geographic locations in Romania were assessed during static, low-speed and high-speed tests. The effectiveness of the Douglas Argos distance angle filter algorithm was then evaluated to ascertain its effect on the minimization of localization errors.

Results. Argos locations received in the tests had larger associated horizontal errors than those indicated by the operator of the Argos system, including under ideal reception conditions. Positional errors were similar to those obtained in other studies outside of Europe. The errors were anisotropic, with larger longitudinal errors for the vast majority of the data. Errors were mostly related to speed of the Argos transmitter at the time of reception, but other factors such as topographical conditions and orientation of antenna at the time of the transmission also contributed to receiving low-quality data. The Douglas-Argos filter successfully excluded the largest errors while retaining a large amount of data when the threshold was set to the local scale $(2 \mathrm{~km})$.

Discussion. Filter selection requires knowledge about the movement patterns and behavior of the species of interest, and the parametrization of the selected filter typically requires a trial and error approach. Selecting the proper filter reduces the errors while retaining a large amount of data. However, the post-processed data typically includes large positional errors; thus, we recommend incorporating Argos error metrics such as error ellipse or use complex modeling approaches when working with filtered data. 
1 EMPIRICAL ANALYSIS AND MODELING OF ARGOS DOPPLER LOCATION

2 ERRORS IN ROMANIA

3

4 Laurentiu Rozylowicz ${ }^{1}$, Florian P. Bodescu ${ }^{2}$, Cristiana M. Ciocanea ${ }^{1}$, Athanasios A. Gavrilidis ${ }^{2}$,

5 Steluta Manolache ${ }^{1}$, Marius L. Matache ${ }^{1}$, Iulia V. Miuํㄹ Ionut C. Moale ${ }^{2}$, Andreea Nita ${ }^{1}$, Viorel

6 D. Popescu ${ }^{1,3}$

7

$8{ }^{1}$ Center for Environmental Research and Impact Studies, University of Bucharest, Bucharest,

9 Romania

$10{ }^{2}$ Multidimension SRL, Bucharest, Romania

$11{ }^{3}$ Biological Sciences, Ohio University, Athens Ohio, USA

12

13 Corresponding author:

14 Laurentiu Rozylowicz ${ }^{1}$

15 University of Bucharest, Center for Environmental Research and Impact Studies, 1 N. Balcescu, 16 010041, Bucharest, Romania

17 email address: laurentiu.rozylowicz@g.unibuc.ro 


\section{ABSTRACT}

20 Background. Advances in wildlife tracking technology have allowed researchers to understand

21 the spatial ecology of many terrestrial and aquatic animal species. Argos Doppler is a technology

22 that is widely used for wildlife tracking owing to the small size and low weight of the Argos

23 transmitters. This allows them to be fitted to small-bodied species. The longer lifespan of the

24 Argos units in comparison to units outfitted with miniaturized global positioning system (GPS)

25 technology has also recommended their use. In practice, large Argos location errors often occur

26 due to communication conditions such as transmitter settings, local environment, and the

27 behavior of the tracked individual.

Methods. Considering the geographic specificity of errors and the lack of benchmark studies in Eastern Europe, the research objectives were: (1) to evaluate the accuracy of Argos Doppler technology under various environmental conditions in Romania, (2) to investigate the effectiveness of straightforward destructive filters for improving Argos Doppler data quality, and (3) to provide guidelines for processing Argos Doppler wildlife monitoring data. The errors associated with Argos locations in four geographic locations in Romania were assessed during static, low-speed and high-speed tests. The effectiveness of the Douglas Argos distance angle filter algorithm was then evaluated to ascertain its effect on the minimization of localization errors.

Results. Argos locations received in the tests had larger associated horizontal errors than those indicated by the operator of the Argos system, including under ideal reception conditions. Positional errors were similar to those obtained in other studies outside of Europe. The errors were anisotropic, with larger longitudinal errors for the vast majority of the data. Errors were mostly related to speed of the Argos transmitter at the time of reception, but other factors such as topographical conditions and orientation of antenna at the time of the transmission also contributed to receiving low-quality data. The Douglas-Argos filter successfully excluded the largest errors while retaining a large amount of data when the threshold was set to the local scale $45(2 \mathrm{~km})$.

Discussion. Filter selection requires knowledge about the movement patterns and behavior of the species of interest, and the parametrization of the selected filter typically requires a trial and error approach. Selecting the proper filter reduces the errors while retaining a large amount of data. 
49 However, the post-processed data typically includes large positional errors; thus, we recommend

50 incorporating Argos error metrics such as error ellipse or use complex modeling approaches 51 when working with filtered data. 


\section{INTRODUCTION}

53 Advances in wildlife tracking technologies allow researchers to track the movement of many

54 terrestrial and aquatic species (Thomas et al. 2012). Movement analysis has evolved from short-

55 term local studies on small numbers of individuals to long-term global studies on hundreds of

56 individuals, allowing researchers to answer more complex questions about animal movement and

57 space use (Block et al. 2011; Sequeira et al. 2018). These data can be included in statistical

58 models and used to understand movement patterns, population redistribution, habitat use, habitat

59 selection, and conservation needs (Bridge et al. 2011; Doherty et al. 2017; Hooten et al. 2017;

60 Pendoley et al. 2014; Pop et al. 2018; Schofield et al. 2013).

61 Collecting good quality movement data remains a challenging task mainly due to technological

62 constraints (Hooten et al. 2017). Well-known tracking technologies such as radio telemetry

63 (VHF telemetry), satellite-based telemetry (GPS, Argos), and light-level geolocation have certain

64 limitations (Bridge et al. 2011). The main challenges are the physical size and the mass of the

65 devices. In particular, the mass of the device must not exceed 5\% of the animal's body-weight

66 (Silvy 2012). Furthermore, transmitters must be protected from environmental hazards and

67 damage and must include a long-lasting battery or alternative power source for consistent one-

68 way or two-way communication (Bridge et al. 2011). As such, devices meeting these parameters

69 can be cumbersome and heavy (Silvy 2012), and not well suited for many small-bodied animals.

70 The most accurate available tracking technology is the Global Positioning System (GPS),

71 capable of a horizontal location accuracy of under $10 \mathrm{~m}$ (Madry 2015). The weight of present-

72 day GPS receivers varies between a minimum of 4 grams (lifespan limited to a few transmission

73 days and suitable for individuals weighing $\sim 80$ grams) to in excess of one kilogram (typically a

74 lifespan averaging 2 years and suitable only for large animals). An alternate option for long-term

75 animal movement studies is the Argos satellite Doppler-based system, which relies on

transmitters with extended lifespans that now weigh less than 4 grams, and are able to deliver an

unlimited number of locations in near real-time (Bridge et al. 2011; Hooten et al. 2017; Thomas

et al. 2012). However, the small size comes at a cost in terms of accuracy of localization

compared to GPS. Thus, data interpretation may pose a challenge for inexperienced users

80 (Rozylowicz et al. 2018). Regardless of the device size, Argos transmitters, or Platform

81 Transmitter Terminals (PTT), provide locations with the same error rate. In addition, the data

82 requires the application of complex control processes, such as filtering and modeling (Thomas et 
83 al. 2012). If the PTT's are equipped with GPS receivers, the location precision can be increased 84 by retaining only validated locations (Lopez et al. 2015). Adding a GPS unit to a PTT device results in increasing the minimum device weight to approximately 20 grams per unit.

86

87 88 89 90

The Argos system utilizes positioning instruments on board six polar-orbiting satellites, in addition to ground-based receiving stations and data processing centers. It delivers near real-time localization of transmitters to end-users. Argos locations are calculated from the Doppler shift of a PTT radio frequency during a satellite pass (CLS 2016). Collecte Localisation Satellites (CLS), the operator of the Argos system, provides several metrics for data quality, such as a location class (LC) based on the number of messages received for each location. The estimated upper bound errors are $250 \mathrm{~m}$ for LC 3 (best accuracy class), $500 \mathrm{~m}$ for LC 2, $1500 \mathrm{~m}$ for LC 1, and over $1500 \mathrm{~m}$ for LC 0. For locations derived from three or fewer messages (LC A, LC B), Argos does not provide error thresholds. Invalid locations are labeled as LC Z and GPS locations as LC G (CLS 2016). CLS pre-processes these locations using one of Argos's nominal filters such as the Least Squares algorithm or the Kalman filter (Lopez et al. 2015). In practice, location errors of 10 to 100 kilometers often occur due to communication conditions driven by the environment or animal behavior (e.g., animal speed, terrain fragmentation, rain, cloud cover, temperature) (Christin et al. 2015; Costa et al. 2010; Douglas et al. 2012; Dubinin et al. 2010; Sauder et al. 2012; Witt et al. 2010). Thus, filtering the data to exclude implausible Argos locations before employing movement analysis has become a standard approach for researchers (Hooten et al. 2017). Furthermore, the quality of data seems to be highly dependent on geographic location. The Argos transmission systems in Eastern Europe are lower in power, their signals being hidden by background radio noise that is present across the Argos frequency (Gros et al. 2006).

Location errors can be filtered using destructive (i.e., removing implausible locations) and reconstructive filters (i.e., evaluation of uncertainty in the estimation of locations) (Douglas et al. 2012). Destructive filters remove duplicates (e.g., identical timestamps), locations outside of a defined range (e.g., thresholds for geometric dilution of precision, latitude, longitude, location class), or locations exceeding a fixed movement rate or a turning angle (Douglas et al. 2012; Kranstauber et al. 2011). One such advanced destructive filter is the Douglas Argos filter algorithm, available on the Movebank database of animal tracking data (Kranstauber et al. 2011). The Douglas Argos filter algorithm uses thresholds to mark the outliers as implausible locations.

13 It is available in three settings: the maximum redundant distance filter (MRD) (which retains 
114 near-consecutive locations within a distance threshold), the Douglas Argos distance angle filter

115 (DAR) (which retains near-consecutive locations within a distance threshold and location-

116 passing movement-rate and turning-angle tests), and the hybrid filter (HYB) (which combines

117 MRD and DAR parameters specifically for migratory species) (Douglas et al. 2012). In contrast,

118 reconstructive filters employ advanced statistical methods to detect animal movement

119 characteristics without removing locations (e.g., discrete-time movement model, correlated

120 random walk state-space models, movement-based kernel density estimates, Bayesian State-

121 Space Models, and hidden Markov models), or model the data using the errors associated with

122 movement (e.g., Argos error ellipse) (Hooten et al. 2017; Jonsen et al. 2005; Lopez et al. 2015;

123 Silva et al. 2014).

124 Considering the behavioral, environmental and geographic specificity of the errors associated 125 with Argos data and the lack of benchmark studies in Eastern Europe, the research objectives for

126 this study are: (1) to provide empirical evidence of the accuracy of locations collected via the

127 Argos Doppler system in Romania, (2) to investigate the effectiveness of straightforward

128 destructive filters for improving Argos data quality, and (3) to provides guidelines for processing

129 Argos wildlife monitoring data in Eastern Europe. The errors associated with Argos locations

130 were assessed in four geographic locations from Romania under three spatial movement

131 conditions: static, low-speed and high-speed. The effectiveness of the Douglas Argos distance

132 angle filter algorithm was then evaluated in terms of location error minimization.

133

134 MATERIALS \& METHODS

135 Trial sites

136 The accuracy of Argos locations was analyzed in four areas in Romania. These areas varied both

137 topographically and in terms of reception conditions and could be categorized as:

138 (1) Urban: two urban parks within a residential area of Romania's largest metropolis, Bucharest

139 (within the Tineretului Park for the static test, $44^{\circ} 24^{\prime} \mathrm{N} 26^{\circ} 06^{\prime} \mathrm{E}$; and the shoreline of Vacaresti

140 Lake for the mobile tests, $\left.44^{\circ} 24^{\prime} \mathrm{N}, 26^{\circ} 07^{\prime} \mathrm{E}\right)$.

141 (2) Unobstructed flat rural lowland: Saveni, Ialomita County $\left(44^{\circ} 35^{\prime}, 27^{\circ} 37^{\prime} \mathrm{E}\right)$.

142 (3) Highly fragmented rural topography: Iron Gates Natural Park, Mehedinti County (44 $41^{\prime} \mathrm{N}$

$\left.14322^{\circ} 21^{\prime} \mathrm{E}\right)$, along the Danube River. 
144 (4) Moderately fragmented rural upland: Sighisoara (within Breite for the static tests, $46^{\circ} 12^{\prime} \mathrm{N}$

$14524^{\circ} 45^{\prime} \mathrm{E}$; and Sighisoara-Apold for the mobile tests, $\left.46^{\circ} 09^{\prime} \mathrm{N} 24^{\circ} 46^{\prime} \mathrm{E}\right)$ ).

146 At all trial sites, three tests were carried out: a static test, a low-speed test, and a high-speed test 147 (Fig. 1).

\section{Experimental protocol}

149 Five Argos PTTs were used, all identical GeoTrack 23g Solar PTT units (GeoTrack Ink., Apex, 150 NC) with a repetition period of 60 seconds. The PTTs were initially programmed for an 8 hours 151 'on' and 43 hours 'off' transmission cycle. They were then manually activated at the start of the 152 working day and restarted if the transmission cycle lasted longer than 8 hours. Daily activation 153 occurred 10 minutes before the first Argos satellite was scheduled to be visible, according to the 154 satellite pass prediction (CLS 2016). During the experiment, a transmission day started after the 155 activation of the PTTs, when the first Argos message was received by a given PTT, and ended 156 after a minimum of 6 hours, when the satellite transmitting the last message was no longer 157 visible to the PTTs. The PTTs were glued on a stake $20 \mathrm{~cm}$ from each other, with their antennas 158 pointing in the same direction towards the sky. Argos messages were processed by CLS using 159 the standard Kalman filter algorithm (CLS 2016), with a predefined average speed of $16 \mathrm{~m} / \mathrm{s}$. To 160 estimate the accuracy of the Argos locations, each Doppler location was matched with a GPS 161 location (Garmin Oregon 650, Garmin Ltd.) obtained within a 5-minute time period. Garmin 162 GPS receivers have a precision of under $10 \mathrm{~m}$ in low-rise residential areas (Beekhuizen et al. 163 2013). GPS locations could thus be considered accurate.

164 Each speed test lasted a total of 6 transmission days, with a minimum of 6 transmission hours per 165 cycle. For static tests, the five PTTs were positioned $30 \mathrm{~cm}$ above ground in unobstructed 166 transmission conditions. For low-speed tests, researchers carried the PTTs attached to a backpack 167 at normal walking speed (4-5 km/h). For the high-speed tests, the PTTs were mounted on a 168 bicycle traveling at $15 \mathrm{~km} / \mathrm{h}$. In each test, the GPS receiver was set to record a location every 30 169 seconds.

\section{Data processing and analyses}

171 Argos messages were downloaded daily. Each Argos message was assigned to the corresponding

172 trial site and movement test. Prior to statistical analysis, the dataset was cleaned to eliminate

173 records without coordinates or with identical timestamps. 
174 The magnitude of spatial errors was estimated using several error metrics. Distances between

175 Argos locations and the corresponding GPS locations were calculated as the geodesic distance

176 using the WGS 1984 reference ellipsoid (i.e., location error, in meters). The direction of the

177 error was calculated as bearing along a rhumb line between the Argos and GPS locations (i.e.,

178 error bearing, $0-360^{\circ}$ ) (Hijmans et al. 2017). Latitudinal and longitudinal errors were calculated

179 as the difference between the UTM coordinates of Argos latitude and longitude and the

180 corresponding GPS latitude and longitude (i.e., Latitudinal and Longitudinal errors in km).

181 Furthermore, Argos locations were classified as "in" or "out" of Argos ellipse error by plotting

182 them in the ArcGIS 10.3 (ESRI, CA) software package along with the ellipse error components

183 provided by CLS for each location (Data S1).

184 The variability of log-transformed location errors was evaluated using linear-mixed effects

185 models with motion (speed: static, low-speed, high-speed), place (trial sites: Saveni, Bucharest,

186 Sighisoara, Iron Gates), and a terrain ruggedness index (TRI) (Riley 1999) as fixed effects and

187 the receiving points (locations generated simultaneously by all transmitting PTTs at a satellite

188 pass) nested within the satellite generating the Argos locations as random effects. Grouping the

189 locations by receiving points allowed control of pseudoreplication and latent variation

190 unaccounted for by the fixed effects (Harrison et al. 2018).

191 Several linear-mixed effects models were fitted using different combinations of fixed effects

192 with the same nested random effects structure using function lmer with restricted maximum

193 likelihood (REML) in the package lme4 (Bates et al. 2015) in program R (R Core Team 2018).

194 To select the best model predicting the variance of log-transformed location errors we used

195 Akaike's Information Criterion, corrected for small sample size (AICc) (Table S1). The model fit

196 was evaluated as the variance in the data explained by fixed effects (marginal R-squared) and

197 collectively by fixed and random effects (conditional R-squared) (Nakagawa \& Schielzeth 2013).

198 To evaluate the effectiveness of the data filters to minimize the location errors when the tracked

199 species move within a given site, we partitioned the data by trial sites and then ran distance,

200 angle, and rate Douglas Argos filter (DAR) on Movebank tracking platform

201 (www.movebank.org) (Douglas et al. 2012; Kranstauber et al. 2011). The two other versions of

202 the Douglas Argos filter are either a truncated version of the distance, angle and rate filter

203 (maximum redundant distance, MRD filter) or specifically designed for migration movement

204 (HYB filter), which was not the case in this experiment (Douglas et al. 2012). 
205 The DAR filter was applied twice: with the threshold radius set to encompass 2 locations which 206 were considered self-confirming (MAXREDUN) at $2 \mathrm{~km}$ (DAR 2) and at $15 \mathrm{~km}$ (DAR 15).

207 Smaller threshold values, such as $2 \mathrm{~km}$ are suitable for local scale movement while larger values 208 (e.g., $15 \mathrm{~km}$ ) are suitable for macro scale movements (Douglas et al. 2012). It is recommended 209 by the authors of the Douglas Argos algorithm to retain locations above LC 1 (locations with 210 higher accuracy class); however, because our test was focused on the effectiveness of this filter

211 at eliminating location errors from the whole dataset, a location class threshold was not provided.

212 The two other user-defined parameters of the DAR filter were kept fixed in both filtering

213 sessions because the experimental conditions were similar. MINRATE (maximum sustained rate

214 of movement over a period of several hours) was set at $15 \mathrm{~km} / \mathrm{h}$ (maximum velocity achieved

215 during the test) and RATECOEF was set at 10 (specifically used for movements following a very 216 circuitous pattern). MINRATE confirms the plausibility of a location based on a reasonable rate

217 of movement that the animal of interest might sustain and RATECOEF is a scaling parameter

218 which influences how the angle between two consecutive locations is evaluated (parameter

219 values vary between 10, for species displaying out-and-back movement, and 40, for species with 220 directional movement) (Douglas et al. 2012). The results of the two user-specific filters (DAR 2 221 and DAR 15) were compared to the unfiltered data. For comparison purposes, the results for two 222 intermediary MAXREDUN thresholds are presented in a supplementary file: $5 \mathrm{~km}$ (DAR 5) and $22310 \mathrm{~km}$ (DAR 10).

224 We used R 3.5.1 (R Core Team 2018) package dplyr (Wickham et al. 2018) for cleaning data, 225 geosphere (Hijmans et al. 2017) for calculating error metrics, dunn.test (Dinno 2017) for testing 226 differences between various datasets, lme4 (Bates et al. 2015), MuMIn (Barton 2018), merTools 227 (Knowles et al. 2018) for linear-mixed effects models, ggpubr (Kassambara 2018), ggeffects 228 (Lüdecke 2018), and openair (Carslaw \& Ropkins 2012) for figures.

229

\section{RESULTS}

231 Between June 2017 and September 2017, the five PTTs received 3705 valid Argos locations

232 (Data S1). Each PTT generated a similar number of locations $\left(\min =717, \max =760, \chi^{2}(\mathrm{df}=4\right.$, $233 \mathrm{n}=3705)=1.86, \mathrm{p}=0.76$ ). For each location, the Argos PTTs transmitted between 1 and 14 234 messages to one of the six polar-orbiting satellites fitted with Argos instruments. The Argos 
235 satellites resulted in the calculation of a dissimilar number of locations $(\mathrm{min}=310$, NOAA-N,

$236 \mathrm{NP}^{\prime} ; \max =890$, NOAA-18, NN, $\left.\chi^{2}(\mathrm{df}=5, \mathrm{n}=3705)=399.87, \mathrm{p}<0.001\right)$.

237 The dataset was dominated by low-quality data, with over $29 \%$ of locations labeled as LC B.

$23846 \%$ of the locations were classified by the CLS as error bounded (Argos LC 3, 2, and 1), from

239 which 14.25\% were of high estimated quality (LC 3, <250 m estimated accuracy) (Table 1).

240 The empirical mean location error for the five PTTs was $3583.66 \mathrm{~m}$ ( $\operatorname{stdev}=8225.97 \mathrm{~m})$.

241 Location errors differed significantly by Argos location classes (Kruskal-Wallis chi-squared =

242 1170.95, $\mathrm{df}=5, \mathrm{p}<0.001$ ), except for the LC 1 and LC A which showed identical ranking. All

243 the error-bounded location classes (Argos LC 3, 2, and 1) had measured errors which were

244 significantly larger than the location-class-specific 68th percentile estimated by CLS. Argos LC

245 A and LC B had smaller associated errors than LC 0, a location class which is considered more

246 accurate by CLS (Fig. 2, Table 1).

247 On average, longitudinal errors were larger $($ mean $=2872 \mathrm{~m}, \mathrm{stdev}=7678 \mathrm{~m})$ than latitudinal

248 errors $($ mean $=1604.4 \mathrm{~m}, \mathrm{stdev}=3272.3 \mathrm{~m})$. This pattern was found to be consistent in all

249 location classes (Table 1). The largest proportion of longitudinal errors were in LC 0 (73.96\% of

250 locations) and LC 1 (73.44\% of locations), while the largest proportion of latitudinal errors was

251 found in the LC B (39.29\%) and LC A (38.42\%) classes. Geographically, most errors were to the

252 East and West, followed by the North-East and South-West. Those oriented toward the North

253 and South were less present in the dataset (Fig. S1, Fig. S2).

254 The best linear mixed model showed that the fixed factors Motion (speed tests) and Place (trial

255 areas) had a significant impact on the errors (Table S1). The fixed factors Motion and Place

256 accounted for $17.45 \%$ of the variance in the error data (marginal R-squared), while the fixed and

257 random structures (reception points nested in the satellite) combined accounted for $56.79 \%$ of

258 the variance (conditional R-squared). The proportion of variance in errors accounted for by the

259 reception points nested in the satellite (Intra Class Correlation Coefficient, ICC) was 41.91\%,

260 while the satellites themselves accounted for only $5.73 \%$, suggesting that reception conditions at

261 transmission time strongly influenced the quality of the data (Table 2).

262 A comparison of the confidence intervals of the fixed factors showed that the locations from

263 motion-controlled trials differed significantly. Errors from high-speed tests were larger than

264 those in the low-speed tests, and errors in the low-speed tests were larger than in the static tests.

265 The mean error for the static tests was $2708.84 \mathrm{~m}$, the mean error for the low-speed tests was 
$2663779.73 \mathrm{~m}$, and the mean error for high-speed tests was $4550 \mathrm{~m}$, (Fig. 3, Table 3). The trial sites

267 also contributed to the error variance, with locations from Iron Gates (a narrow valley)

268 generating larger errors when compared to locations from the other sampling areas. As a

269 comparative example, the mean error for Iron Gates was $4698.35 \mathrm{~m}$ and the mean error for

270 Saveni was $3122.01 \mathrm{~m}$ (Fig. 3, Table 4). Interestingly, it was found that substantial errors existed

271 in the static tests from Iron Gates which were as large as the location errors associated with the

272 low-speed tests conducted in Saveni, Bucharest, and Sighisoara (Fig. 3).

273 The DAR filter applied to raw data, successfully excluded the largest errors when MAXREDUN

274 was defined for local (2 km, DAR 2) and regional (15 km, DAR 15) scales of study. However,

275 the DAR 2 filter was more effective at excluding large errors, by retaining $84.35 \%$ of the initial

276 locations compared to $94.82 \%$ for the DAR 15 filter (Table S2, Table S3). The mean error for the

277 DAR 2 filtered data was 2313.51 meters ( $(\mathrm{tddev}=3134.67$ ), a $35.45 \%$ improvement compared to

278 the error associated with the raw data, while the improvement after the DAR 15 filter was

279 applied was only $27.05 \%$. The DAR 15 filter retained almost all the locations in LC 3, LC 2 and

280 LC 1 classes, while the DAR 2 filter altered the number of LC 2 and LC 1 locations slightly. The

281 most heavily-impacted location class was LC 0 - the class with the most substantial errors

282 amongst the data - with only $68.35 \%$ of locations retained by the DAR 2 filter and $90.42 \%$ by the

283 DAR 15 filter (Table S2, Table S3, Fig. 4). The intermediate thresholds (DAR 5 and DAR 10)

284 did not improved the data accuracy in comparison to DAR 2, and the results were only

285 marginally different when compared to DAR 15 (Fig. S3). Douglas Argos algorithms filtered

286 longitudinal and latitudinal errors equally; thus, the filtered data are also anisotropic, with the

287 longitudinal errors larger than the latitudinal errors (Fig. 5).

288

289 DISCUSSION

290 The accuracy of the Argos Doppler locations received from Romania was negatively influenced

291 by the movement speed and topographic characteristics of the trial sites. The empirical data

292 showed that Argos locations yielded a lower accuracy, even in stationary tests performed in

293 unobstructed areas. This suggests that Argos Doppler telemetry data must undergo a

294 comprehensive filtering process before being used in movement analysis. 
295 In our experiment, 14\% of locations were considered category LC 3, the most accurate Argos 296 location class (CLS 2016). However, the $68^{\text {th }}$ percentile of LC 3 locations was twice as large as 297 the $68^{\text {th }}$ percentile provided by CLS as the upper bound error (520.85 m vs. $250 \mathrm{~m}$ ). All error298 bounded Argos locations classes (LC 2, LC 1, and LC 0) included larger positional errors than 299 those indicated by CLS (CLS 2016), which is in line with the results demonstrated in other 300 controlled and real-life studies. For example, a stationary and mobile test in Southern Russia

301 (Dubinin et al. 2010) and tests on marine species (Costa et al. 2010) yielded errors similar to ours 302 for LC 3 data. Data recovered from these other studies and our results indicate higher errors than 303 those indicated by CLS for all location classes. LC 0 was the most inaccurate location class $\left(68^{\text {th }}\right.$ 304 percentile $=5877.38 \mathrm{~m}$ ), which corroborates the results of other studies (Douglas et al. 2012;

305 Lowther et al. 2015). This suggests that LC 0 locations must be filtered together with LC A and 306 LC B, and should not be considered an accurate location class. Argos errors are not isotropic, 307 and longitudinal errors were larger than latitudinal errors (CLS 2016; Douglas et al. 2012), as 308 already reported by all benchmark studies (Lowther et al. 2015; Sauder et al. 2012; Witt et al. 309 2010). In this study, the mean latitudinal errors for LC 3, LC 2, and LC 1 were only slightly 310 larger than the CLS $68^{\text {th }}$ percentile for the respective location classes. However, these data are 311 not likely to be useful for movement studies, such as home-range analysis (Hooten et al. 2017)

312 since longitudinal errors were significant even in optimal reception environments (e.g., flat areas, 313 unobstructed by vegetation). South-Eastern Europe is considered an area with poor reception

314 quality due to the broadband noise covering the Argos $401.65 \mathrm{MHz} \pm 30 \mathrm{kHz}$ frequency (Gros et 315 al. 2006), which might have a negative impact on quantity and quality of data. Since these errors

316 were similar to those obtained in other studies outside of Europe, the broadband noise affecting

317 Southeastern Europe (Gros et al. 2006) seems to have had only a minimal influence on the 318 accuracy of Argos data.

319 The accuracy of Argos Doppler locations is influenced by a plethora of factors such as the PTTs' 320 repetition rate, topography, vegetation, terrain ruggedness, electromagnetic noise, and 321 geographic area (Freitas et al. 2008; Lowther et al. 2015; Nicholls et al. 2007; Sauder et al. 322 2012). The best linear mixed effects model for this study showed that the movement speed of the 323 PTT had the most significant influence on Argos location errors, while the trial area contributed 324 only marginally to the variation in errors. As expected, motion-controlled tests generated 325 significantly varying errors. Static tests generated smaller errors than low-speed tests, and high- 
326 speed tests generated larger errors than low-speed tests. However, topographical obstruction of 327 the sky influenced data acquisition. Data obtained from the highly-fragmented Iron-Gates trial 328 area contained larger errors than the other three trial areas, including Bucharest city potentially 329 affected by electromagnetic interference (Gros et al. 2006). In the Iron Gates area, the static test 330 generated positional errors as large as in the low-speed motion tests performed in the other three 331 areas. This suggests that locations from fragmented areas may be highly imprecise and can lead 332 to biased conclusions about animal movement and location if not adequately filtered (Lopez et 333 al. 2015). The variance explained by the random part of the linear mixed effects model suggests 334 that the satellite detecting the location of the PTT had a minimal impact on accuracy, while the 335 dominant source of positional errors were probably due to other random factors, such as poor

336 line of sight to the satellite as a result of local topography, the presence of obstructing vegetation 337 or the relative orientation of the respective PTT with respect to the sky (Christin et al. 2015; 338 Doherty et al. 2017; Dubinin et al. 2010; Soutullo et al. 2007).

339 Due to the large positional errors, Argos Doppler data should be filtered or modeled, considering 340 the uncertainty of locations (McClintock et al. 2014). Data filtering is a challenge, as the aim is 341 to reduce low-quality data as much as possible while retaining the necessary amount of data for 342 analysis (Hooten et al. 2017). In the filtering exercise conducted in this study, we tested the 343 effect of the Douglas Argos distance, angle, and rate filter. This filter retains spatially redundant

344 locations, passing movement rates, and turning angle tests (Douglas et al. 2012). The results

345 indicated that the selection of a proper self-validating distance threshold significantly reduces the 346 errors while retaining a large amount of data. In this study, a larger threshold, MAXREDUN =

$34715 \mathrm{~km}$, reduced the efficacy of the filter considerably by retaining $10 \%$ more locations than when

348 the threshold was set at $2 \mathrm{~km}$. The differences between the two approaches suggested that

349 previous knowledge of movement behavior of species of interest is essential to ensure good 350 quality data. For example, if the species of interest is known to perform frequent long-distance 351 movements, then a larger MAXREDUN is required. The DAR filter was tested by targeting all 352 the location classes; however, LC 3, LC 2, and LC 1 were only slightly impacted, and thus it is 353 recommended to run the filter using LC 1 as the threshold location class as suggested by Douglas 354 et al. (2012).

355 Even if selecting the optimal threshold, the post-processed data may include large positional 356 errors; therefore, we recommend incorporating Argos error metrics such as error ellipse into 
357 models (McClintock et al. 2014). As an alternative, complex statistical approaches such as state358 space modeling can be used instead of standard movement analysis (Hooten et al. 2017). While 359 the results were provided based on the distance, angle, and rate filter which fitted the data, other 360 available filtering approaches might be more effective for a given species (e.g., speed filters,

361 Douglas Argos MRD, Douglas Argos HYB).

362

\section{CONCLUSIONS}

364 To provide guidance for processing Argos Doppler-derived locations obtained from Eastern 365 Europe, we assessed the errors associated with Argos locations in four geographic locations in

366 Romania using static, low-speed and high-speed tests. The effectiveness of destructive filters was 367 evaluated in terms of the minimization of location errors, using the Douglas Argos distance angle 368 filter algorithm as an example. The results indicated that the received Argos locations had larger positional errors than those indicated by the operator of the Argos system. This included cases where the reception conditions were ideal. The magnitude of the errors varied among location classes; however, locations in the LC 0 class were prone to large errors. Positional errors were anisotropic, predominantly oriented East and West, which resulted in larger longitudinal errors. Errors were mostly related to the speed of the transmitters and the reception conditions at the time of transmission (e.g., the orientation of the transmitter with respect to the sky), but other factors such as topography contributed to receiving low-accuracy data as well. The destructive Douglas Argos distance angle filter removed between 15\% (self-confirming distance threshold = $2 \mathrm{~km}$ ) and $5 \%$ (threshold $=15 \mathrm{~km}$ ) of locations. However, the mean errors remained larger than those indicated by the operator of Argos system. The Argos data should therefore be used with caution in movement ecology studies, especially for species with small home ranges, such as songbirds, reptiles, or small mammals. Filter selection for data processing requires knowledge about the movement patterns and behaviors of the species of interest, and parametrization of the selected filter must follow a trial and error approach. Argos Doppler is unsuitable for movement analysis of species with limited movement capabilities. GPS tags would be preferable for such species, enabling detailed analysis of habitat selection and movement, with the caveat that storeon-board systems might be required owing to the larger sizes of the units that send data remotely via satellite. 
388

389

390

391

392

393

394

395

396

397

398

399

400

401

402

403

404

405

406

407

408

409

410

411

412

413

414

415

416

417

418

419

420

421

422

423

424

425

426

427

428

429

\section{REFERENCES}

Barton K. 2018. Package 'MuMIn'. Multi-Model Inference. v. 1.42.1. R package. https://CRAN.R-project.org/package=MuMIn

Bates D, Mächler M, Bolker B, and Walker S. 2015. Fitting linear mixed-effects models using lme4. Journal of Statistical Software 67. 10.18637/jss.v067.i01

Beekhuizen J, Kromhout H, Huss A, and Vermeulen R. 2013. Performance of GPS-devices for environmental exposure assessment. Journal of Exposure Science and Environmental Epidemiology 23:498. 10.1038/jes.2012.81

Block BA, Jonsen ID, Jorgensen SJ, Winship AJ, Shaffer SA, Bograd SJ, Hazen EL, Foley DG, Breed G, and Harrison A-L. 2011. Tracking apex marine predator movements in a dynamic ocean. Nature 475:86. 10.1038/nature10082

Bridge ES, Thorup K, Bowlin MS, Chilson PB, Diehl RH, Fléron RW, Hartl P, Kays R, Kelly JF, and Robinson WD. 2011. Technology on the move: recent and forthcoming innovations for tracking migratory birds. Bioscience 61:689-698. 10.1525/bio.2011.61.9.7

Carslaw DC, and Ropkins K. 2012. Openair - an R package for air quality data analysis. Environmental Modelling \& Software 27:52-61. 10.1016/j.envsoft.2011.09.008

Christin S, St-Laurent MH, and Berteaux D. 2015. Evaluation of Argos Telemetry Accuracy in the High-Arctic and Implications for the Estimation of Home-Range Size. PLoS One 10:e0141999. 10.1371/journal.pone.0141999

CLS. 2016. Argos User's Manual. Available at http://www.argos-system.org/manual/ (accessed 07/22/2018).

Costa DP, Robinson PW, Arnould JP, Harrison AL, Simmons SE, Hassrick JL, Hoskins AJ, Kirkman SP, Oosthuizen H, Villegas-Amtmann S, and Crocker DE. 2010. Accuracy of ARGOS locations of Pinnipeds at-sea estimated using Fastloc GPS. PLoS One 5:e8677. 10.1371/journal.pone.0008677

Dinno A. 2017. dunn. test: Dunn's test of multiple comparisons using rank sums. v. 1.3.5. R package. https://CRAN.R-project.org/package=dunn.test

Doherty P, Baxter J, Gell F, Godley B, Graham R, Hall G, Hall J, Hawkes L, Henderson S, and Johnson L. 2017. Long-term satellite tracking reveals variable seasonal migration strategies of basking sharks in the north-east Atlantic. Scientific reports 7:42837. 10.1038/srep42837

Douglas DC, Weinzierl R, C. Davidson S, Kays R, Wikelski M, Bohrer G, and Giuggioli L. 2012. Moderating Argos location errors in animal tracking data. Methods in Ecology and Evolution 3:999-1007. 10.1111/j.2041-210X.2012.00245.X

Dubinin M, Lushchekina A, and Radeloff VC. 2010. Performance and accuracy of Argos transmitters for wildlife monitoring in Southern Russia. European Journal of Wildlife Research 56:459-463. 10.1007/s10344-009-0354-4

Freitas C, Lydersen C, Fedak MA, and Kovacs KM. 2008. A simple new algorithm to filter marine mammal Argos locations. Marine Mammal Science 24:315-325. 10.1111/j.17487692.2007.00180.x

Gros P, Malardé J, and Woodward B. 2006. Argos performance in Europe. Part 2. Tracker News $7: 8$. 
430 Harrison XA, Donaldson L, Correa-Cano ME, Evans J, Fisher DN, Goodwin CED, Robinson BS,

431

432

433

434

435

436

437

438

439

440

441

442

443

444

445

446

447

448

449

450

451

452

453

454

455

456

457

458

459

460

461

462

463

464

465

466

467

468

469

470

471

472

473

474

Hodgson DJ, and Inger R. 2018. A brief introduction to mixed effects modelling and multimodel inference in ecology. PeerJ 6:e4794. 10.7717/peerj.4794

Hijmans RJ, Williams E, and Vennes C. 2017. Package 'geosphere'. Spherical Trigonometry. v. 1.5-7. R package. https://CRAN.R-project.org/package=geosphere.

Hooten MB, Johnson DS, McClintock BT, and Morales JM. 2017. Animal movement: statistical models for telemetry data. Boca Raton: CRC Press.

Jonsen ID, Flemming JM, and Myers RA. 2005. Robust state-space modeling of animal movement data. Ecology 86:2874-2880.

Kassambara A. 2018. ggpubr: 'ggplot2' Based Publication Ready Plot. v. 0.1.7. R package. https://CRAN.R-project.org/package=ggpubr.

Knowles JE, Frederick C, and Whitworth A. 2018. merTools: Tools for Analyzing Mixed Effect Regression Models. v 0.4.1. R package. https://CRAN.R-project.org/package=merTools.

Kranstauber B, Cameron A, Weinzerl R, Fountain T, Tilak S, Wikelski M, and Kays R. 2011. The Movebank data model for animal tracking. Environmental Modelling \& Software 26:834835. 10.1016/j.envsoft.2010.12.005

Lopez R, Malardé J-P, Danès P, and Gaspar P. 2015. Improving Argos Doppler location using multiple-model smoothing. Animal Biotelemetry 3:32. 10.1186/s40317-015-0073-4

Lowther AD, Lydersen C, Fedak MA, Lovell P, and Kovacs KM. 2015. The Argos-CLS Kalman Filter: Error Structures and State-Space Modelling Relative to Fastloc GPS Data. PLoS One 10:e124754. 10.1371/journal.pone.0124754

Lüdecke D. 2018. ggeffects: Create Tidy Data Frames of Marginal Effects for 'ggplot' from Model Outputs. v. 0.5.0. R package. https://CRAN.R-project.org/package=ggeffects.

Madry S. 2015. Global navigation satellite systems and their applications. New York: Springer.

McClintock BT, London JM, Cameron MF, and Boveng PL. 2014. Modelling animal movement using the Argos satellite telemetry location error ellipse. Methods in Ecology and Evolution 6:266-277. 10.1111/2041-210X.12311

Nakagawa S, and Schielzeth H. 2013. A general and simple method for obtaining R2 from generalized linear mixed-effects models. Methods in Ecology and Evolution 4:133-142. 10.1111/j.2041-210x.2012.00261.x

Nicholls D, Robertson C, and Murray M. 2007. Measuring accuracy and precision for CLS: Argos satellite telemetry locations. Notornis 54:137-157.

Pendoley K, Schofield G, Whittock P, Ierodiaconou D, and Hays G. 2014. Protected species use of a coastal marine migratory corridor connecting marine protected areas. Marine Biology 161:1455-1466. 10.1007/s00227-014-2433-7

Pop IM, Bereczky L, Chiriac S, Iosif R, Nita A, Popescu VD, and Rozylowicz L. 2018. Movement ecology of brown bears (Ursus arctos) in the Romanian Eastern Carpathians. Nature conservation 26:15-31. 10.3897/natureconservation.26.22955

R Core Team. 2018. R: A language and environment for statistical computing. Vienna, Austria: the R Foundation for Statistical Computing.

Riley SJ., DeGloria SD, and Elliot SD. 1999. A terrain ruggedness index that quantifies topographic heterogeneity. Intermountain Journal of sciences 5:23-27.

Rozylowicz L, Bodescu FP, Gavrilidis AA, Miu IV, Moale C, Manolache S, Nita A, Matache ML, and Ciocanea CM. 2018. Tehnici de monitorizare a deplasărilor animalelor sălbatice. Manual. Bucharest: University of Bucharest. 10.5281/zenodo.1344840

PeerJ reviewing PDF | (2018:09:31068:2:0:NEW 21 Dec 2018) 
475

476

477

478

479

480

481

482

483

484

485

486

487

488

489

490

491

492

493

494

495

496

497

498

499
Sauder JD, Rachlow JL, and Wiest MM. 2012. Influence of topography and canopy cover on argos satellite telemetry performance. Wildlife Society Bulletin 36:813-819. 10.1002/wsb.157

Schofield G, Scott R, Dimadi A, Fossette S, Katselidis KA, Koutsoubas D, Lilley MK, Pantis JD, Karagouni AD, and Hays GC. 2013. Evidence-based marine protected area planning for a highly mobile endangered marine vertebrate. Biological Conservation 161:101-109. 10.1016/j.biocon.2013.03.004

Sequeira AM, Rodríguez JP, Eguíluz VM, Harcourt R, Hindell M, Sims DW, Duarte CM, Costa DP, Fernández-Gracia J, and Ferreira LC. 2018. Convergence of marine megafauna movement patterns in coastal and open oceans. Proceedings of the National Academy of Sciences: 201716137. 10.1073/pnas.1716137115

Silva MA, Jonsen I, Russell DJ, Prieto R, Thompson D, and Baumgartner MF. 2014. Assessing performance of Bayesian state-space models fit to Argos satellite telemetry locations processed with Kalman filtering. PLoS One 9:e92277. 10.1371/journal.pone.0092277

Silvy NJ. 2012. The Wildlife Techniques Manual: Volume 1: Research. Volume 2: Management. Baltimore: JHU Press.

Soutullo A, Cadahia L, Urios V, Ferrer M, and Negro JJ. 2007. Accuracy of Lightweight Satellite Telemetry: a Case Study in the Iberian Peninsula. Journal of Wildlife Management 71:1010-1015. 10.2193/2006-042

Thomas B, Holland JD, and Minot EO. 2012. Wildlife tracking technology options and cost considerations. Wildlife Research 38:653-663. 10.1071/WR10211

Wickham H, Francois R, Henry L, and Müller K. 2018. dplyr: A grammar of data manipulation. v 0.7.6. R package. https://CRAN.R-project.org/package=dplyr.

Witt MJ, Åkesson S, Broderick AC, Coyne MS, Ellick J, Formia A, Hays GC, Luschi P, Stroud S, and Godley BJ. 2010. Assessing accuracy and utility of satellite-tracking data using Argoslinked Fastloc-GPS. Animal Behaviour 80:571-581. 10.1016/j.anbehav.2010.05.022 


\section{Figure 1 (on next page)}

Trial sites for the motion-controlled tests within Romania (static, low-speed, highspeed). 


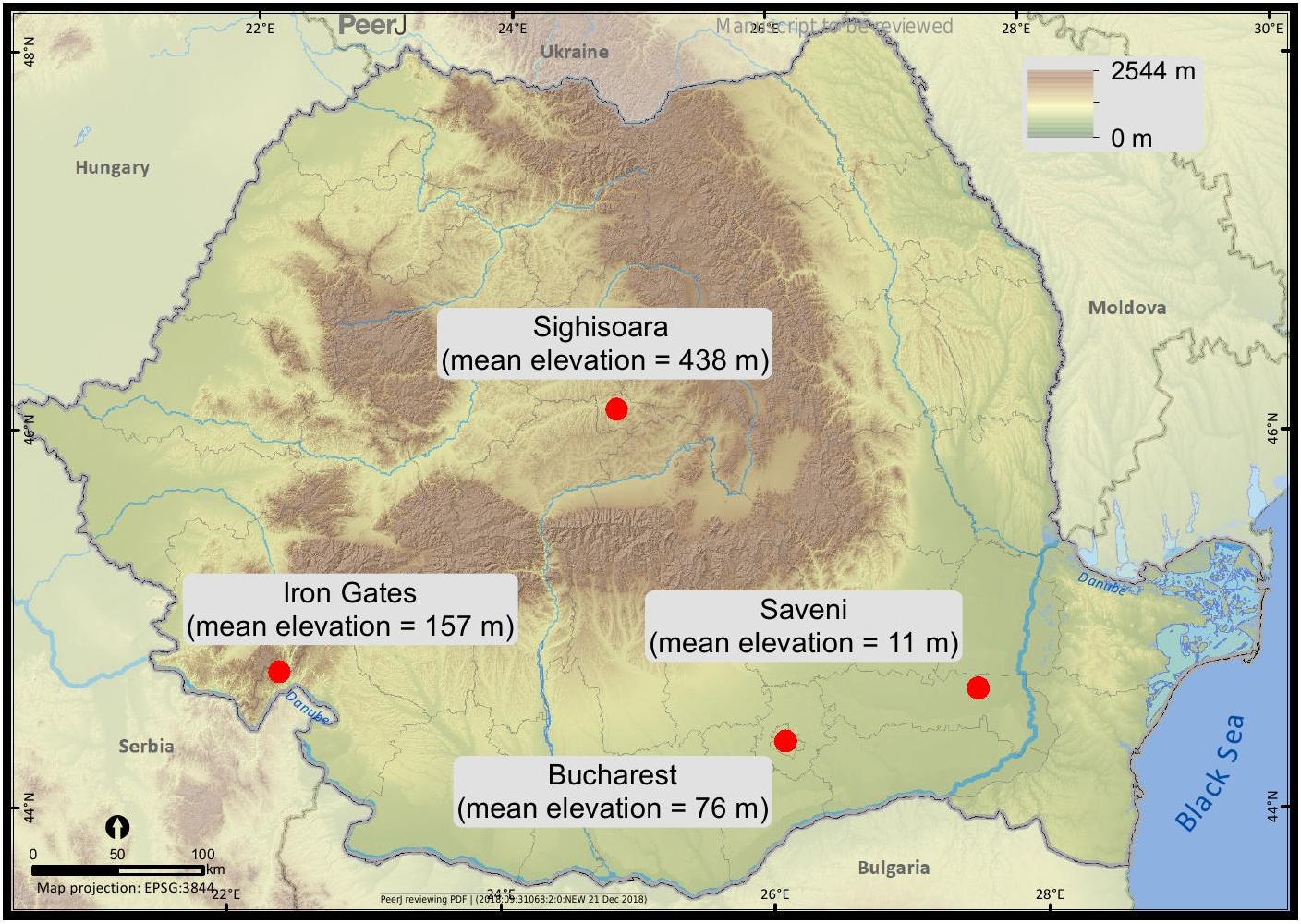


Figure 2 (on next page)

Cumulative distribution of Argos location errors $(\mathrm{km})$ partitioned by Argos location classes (LC).

The 68th percentile of measured errors is larger than the 68th percentile provided by Argos CLS for error bounded LCs (upper error LC 3, LC 2 and LC1). 
Figure 3 (on next page)

Mean $( \pm 95 \% \mathrm{Cl})$ fitted values for the best mixed-effects model predicting Argos location errors by Motion and Place (trial site). 


\section{Figure 4 (on next page)}

Effectiveness of Douglas Argos filter (DAR) in moderating Argos location errors by location class.

NoF $=$ unfiltered data, DAR $2=$ Douglas Argos DAR with MAXREDUN $=2 \mathrm{~km}$, DAR $15=$ Douglas Argos DAR with MAXREDUN $=15 \mathrm{~km}$. 


\section{Figure $\mathbf{5}$ (on next page)}

Latitudinal and longitudinal errors ( $\mathrm{km}$ from GPS locations) for LC 0, LC A, LC B, and all LCs (red $=$ rejected Argos locations; blue $=$ accepted Argos locations). 


\section{Table $\mathbf{1}$ (on next page)}

Location error metrics for all Argos location classes (3705 valid locations received on four trial sites within Romania, during three motion-controlled tests). 


\begin{tabular}{|c|c|c|c|c|c|c|c|}
\hline $\begin{array}{l}\text { Location } \\
\text { class }\end{array}$ & $\begin{array}{l}\text { Sample } \\
\text { size }\end{array}$ & $\begin{array}{l}\text { Mean } \\
\text { error } \\
\text { (stdev), } \\
\text { meters }\end{array}$ & $\begin{array}{l}68^{\text {th }} \\
\text { percentile } \\
\text { of errors, } \\
\text { meters }\end{array}$ & $\begin{array}{l}\text { Mean error } \\
\text { longitude } \\
\text { (stdev), } \\
\text { meters }\end{array}$ & $\begin{array}{l}\text { Mean } \\
\text { error } \\
\text { latitude } \\
\text { (stdev), } \\
\text { meters } \\
\end{array}$ & $\begin{array}{l}\% \% \\
\text { locations } \\
\text { in error } \\
\text { ellipse }\end{array}$ & $\begin{array}{l}\% \\
\text { locations } \\
\text { out of } \\
\text { error } \\
\text { ellipse } \\
\end{array}$ \\
\hline LC 3 & 528 & $\begin{array}{l}578.61 \\
(802.52)\end{array}$ & 520.85 & $\begin{array}{l}466.71 \\
(744.47)\end{array}$ & $\begin{array}{l}254.79 \\
(375.95)\end{array}$ & 10.42 & 89.58 \\
\hline LC 2 & 520 & $\begin{array}{l}1230.64 \\
(1281.56)\end{array}$ & 1383.81 & $\begin{array}{l}969.24 \\
(1099.82)\end{array}$ & $\begin{array}{l}580.09 \\
(818.49)\end{array}$ & 4.62 & 95.38 \\
\hline LC 1 & 674 & $\begin{array}{l}2222.78 \\
(2466.15)\end{array}$ & 2280.64 & $\begin{array}{l}1784.74 \\
(2158.28)\end{array}$ & $\begin{array}{l}1010.66 \\
(1467.00)\end{array}$ & 5.64 & 94.36 \\
\hline LC 0 & 376 & $\begin{array}{l}7127.17 \\
(14869.71)\end{array}$ & 5877.38 & $\begin{array}{l}6195.25 \\
(14492.92)\end{array}$ & $\begin{array}{l}2630.38 \\
(4064.45)\end{array}$ & 11.17 & 88.23 \\
\hline $\mathrm{LC} A$ & 505 & $\begin{array}{l}3669.57 \\
(6816.14)\end{array}$ & 2981.35 & $\begin{array}{l}2894.15 \\
(6484.07)\end{array}$ & $\begin{array}{l}1622.35 \\
(2617.89)\end{array}$ & 9.90 & 90.10 \\
\hline LC B & 1102 & $\begin{array}{l}5717.70 \\
(10456.50)\end{array}$ & 4820.25 & $\begin{array}{l}4444.84 \\
(9611.44)\end{array}$ & $\begin{array}{l}2739.37 \\
(4725.23)\end{array}$ & 28.04 & 71.96 \\
\hline Total & 3705 & $\begin{array}{l}3583.66 \\
(8225.96)\end{array}$ & 2758.73 & $\begin{array}{l}2872.49 \\
7677.608\end{array}$ & $\begin{array}{l}1604.44 \\
(3272.32)\end{array}$ & 13.98 & 86.02 \\
\hline
\end{tabular}


Table 2 (on next page)

Summary of best mixed effect model (log errors $\sim$ Motion $-1+$ Place + (1|Satellite/Reception point). Saveni trial site is kept as reference. 


\begin{tabular}{llllll}
\hline Parameter & $\beta$ & SE & t-value & Lower CI & Upper CI \\
\hline Static & 2.89 & 0.06 & 48.35 & 2.771 & 3.016 \\
Low-speed & 0.38 & 0.03 & 11.74 & 0.319 & 0.446 \\
High-speed & 0.57 & 0.03 & 17.08 & 0.501 & 0.630 \\
Bucharest & -0.03 & 0.04 & -0.90 & -0.103 & 0.038 \\
Iron Gates & 0.13 & 0.04 & 3.65 & 0.061 & 0.205 \\
Sighisoara & -0.02 & 0.04 & -0.45 & -0.093 & 0.058 \\
\hline
\end{tabular}

1 


\section{Table 3(on next page)}

Location error metrics in the three motion-controlled tests carried out within Romania. 


\begin{tabular}{|c|c|c|c|c|c|c|}
\hline Motion & $\begin{array}{l}\text { Sample } \\
\text { size }\end{array}$ & $\begin{array}{l}\text { Mean } \\
\text { error } \\
\text { (stdev), } \\
\text { meters }\end{array}$ & $\begin{array}{l}\text { Mean error } \\
\text { longitude } \\
(\text { stdev }), \text { meters }\end{array}$ & $\begin{array}{l}\text { Mean error } \\
\text { latitude } \\
\text { (stdev), } \\
\text { meters }\end{array}$ & $\begin{array}{l}\% \\
\text { locations } \\
\text { in error } \\
\text { ellipse }\end{array}$ & $\begin{array}{l}\% \\
\text { locations } \\
\text { out of } \\
\text { error } \\
\text { ellipse } \\
\end{array}$ \\
\hline Static & 1496 & $\begin{array}{l}2708.84 \\
(9588.76)\end{array}$ & $\begin{array}{l}2315.32 \\
(9215.04)\end{array}$ & $\begin{array}{l}1042.22 \\
(2810.01)\end{array}$ & 16.51 & 81.68 \\
\hline $\begin{array}{l}\text { Low- } \\
\text { speed }\end{array}$ & 1137 & $\begin{array}{l}3779.73 \\
(7779.31)\end{array}$ & $\begin{array}{l}2879.02 \\
(6871.40)\end{array}$ & $\begin{array}{l}1851.93 \\
(3977.74)\end{array}$ & 11.96 & 88.04 \\
\hline $\begin{array}{l}\text { High- } \\
\text { speed }\end{array}$ & 1099 & $\begin{array}{l}4550.15 \\
(6381.86)\end{array}$ & $\begin{array}{l}3610.44 \\
(5958.59)\end{array}$ & $\begin{array}{l}2099.89 \\
(2909.25)\end{array}$ & 12.28 & 87.72 \\
\hline
\end{tabular}




\section{Table 4(on next page)}

Location error metrics in the four trial sites within Romania. 


\begin{tabular}{lllllll}
\hline $\begin{array}{l}\text { Place (trial } \\
\text { site) }\end{array}$ & $\begin{array}{l}\text { Sample } \\
\text { size }\end{array}$ & $\begin{array}{l}\text { Mean } \\
\text { error } \\
\text { (stdev), } \\
\text { meters }\end{array}$ & $\begin{array}{l}\text { Mean error } \\
\text { longitude } \\
(\text { stdev), meters }\end{array}$ & $\begin{array}{l}\text { Mean error } \\
\text { latitude } \\
\text { (stdev), } \\
\text { meters }\end{array}$ & $\begin{array}{l}\% \\
\text { locations } \\
\text { in error } \\
\text { ellipse }\end{array}$ & $\begin{array}{l}\% \\
\text { locations } \\
\text { out of } \\
\text { error } \\
\text { ellipse }\end{array}$ \\
\hline Saveni & 1106 & $\begin{array}{l}3122.01 \\
(5862.75)\end{array}$ & $\begin{array}{l}2489.22 \\
(5427.42)\end{array}$ & $\begin{array}{l}1410.09 \\
(2539.10)\end{array}$ & 13.29 & 86.71 \\
Bucharest & 969 & $\begin{array}{l}3311.57 \\
(7146.49)\end{array}$ & $\begin{array}{l}2595.00 \\
(6438.32)\end{array}$ & $\begin{array}{l}1545.76 \\
(3379.37)\end{array}$ & 16.10 & 83.90 \\
Sighisoara & 734 & $\begin{array}{l}3277.75 \\
(6439.44)\end{array}$ & $\begin{array}{l}2615.05 \\
(5982.89)\end{array}$ & $\begin{array}{l}1529.57 \\
(2690.64)\end{array}$ & 12.26 & 87.74 \\
Iron Gates & 896 & $\begin{array}{l}4698.35 \\
(12113.6)\end{array}$ & $\begin{array}{l}3856.52 \\
(11495.36)\end{array}$ & $\begin{array}{l}1969.13 \\
(4229.34)\end{array}$ & 13.95 & 86.05 \\
\hline
\end{tabular}

